\title{
Persistent sputum cellularity and neutrophils may predict bronchiectasis
}

\author{
Nicole Drost MD FRCPC ${ }^{1}$, Liesel D'silva MD¹, Ryan Rebello MD FRCPC ${ }^{2}$, Ann Efthimiadis MLT ${ }^{1}$, \\ Frederick E Hargreave MD FRCP ${ }^{1}$, Parameswaran Nair MD PhD FRCP FRCPC ${ }^{1}$
}

\begin{abstract}
N Drost, L D'silva, R Rebello, A Efthimiadis, FE Hargreave, P Nair. Persistent sputum cellularity and neutrophils may predict bronchiectasis. Can Respir J 2011;18(4):221-224.
\end{abstract}

BACKGROUND: Quantitative cell counts in sputum provide an accurate assessment of the type and severity of bronchitis.

OBJECTIVE: To examine whether sputum cell counts could identify bronchiectasis in patients with recurrent bronchitis.

METHODS: A retrospective survey of a clinical database (January 2004 to January 2005) of quantitative cell counts from sputum selected from expectorate in patients with obstructive airways diseases was used to identify predictors of bronchiectasis using ROC curves. This was prospectively evaluated (February 2005 to April 2008) using high-resolution computed tomography scans of thorax that were independently scored by a radiologist who was blinded to the clinical details.

RESULTS: The retrospective survey identified 41 patients with bronchiectasis among 490 patients with airway diseases. Total cell count of $60 \times 10^{6} / \mathrm{g}$ or greater of the selected sputum with predominant neutrophils on two occasions had a sensitivity of $86.7 \%$, a specificity of $87.5 \%$, and positive and negative predictive values of $93 \%$ and $78 \%$, respectively, to identify bronchiectasis. In the prospective study, 10 of 14 (71\%) patients who met these criteria were identified to have bronchiectasis. Both total cell count and the percentage of neutrophils correlated with radiographic bronchiectasis severity.

CONCLUSIONS: Persistent or recurrent intense sputum cellularity with neutrophilia is suggestive of bronchiectasis.

Key Words: Bronchiectasis; Neutrophil; Sputum cell counts

$\mathrm{B}$ ronchiectasis is a chronic suppurative airway disease of diverse etiology. Neutrophil recruitment to the airways by inflammatory cytokines and mediators play an important role in mediating the pathological changes associated with development of bronchiectasis (1). Airway neutrophils are the predominant cells found in bronchoalveolar lavage fluid from such patients (2). Biopsies of bronchial mucosa from bronchiectatic patients show high neutrophil density in the lamina propria $(3,4)$. Quantitative cell counts in sputum selected from saliva provide a reliable and valid measurement of the type and severity of the bronchitis component in a variety of airway diseases including bronchiectasis and cystic fibrosis (5). Although the number of neutrophils and neutrophil activation products have been reported to be increased in the sputum of patients with bronchiectasis, it is not known whether these could be used as a predictor of bronchiectasis. The objective of the present study was to examine the accuracy and measurement properties of quantitative sputum cell counts expressed per gram of selected sputum to identify bronchiectasis detected by high-resolution computed tomography (HRCT) scans of the thorax.

\section{METHODS}

\section{Design}

A retrospective database survey of 751 consecutive sputum cell counts from 490 patients with clinically stable obstructive airway diseases (300 men, mean age 42 years, mean forced expiratory volume in $1 \mathrm{~s}$ $\left[\mathrm{FEV}_{1}\right]$ of $2.2 \mathrm{~L}$ [68\% predicted], 22\% current smokers) performed

\section{La cellularité persistante des expectorations et les neutrophiles peuvent permettre de prédire une bronchiectasie}

HISTORIQUE : La numération cellulaire quantitative des expectorations fournit une évaluation précise du type et de la gravité de la bronchite.

OBJECTIF : Examiner si la numération cellulaire des expectorations peut permettre de dépister une bronchiectasie chez les patients ayant une bronchite récurrente.

MÉTHODOLOGIE : Les chercheurs ont procédé à l'étude rétrospective d'une base de données cliniques (de janvier 2004 à janvier 2005) pour obtenir la numération cellulaire quantitative des expectorations à partir des crachats de patients ayant une maladie pulmonaire obstructive afin de repérer les prédicteurs de bronchiectasie au moyen des courbes de fonction d'efficacité du récepteur. Ils en ont fait une évaluation prospective (de février 2005 à avril 2008) au moyen de la tomodensitométrie à haute résolution du thorax, évaluée de manière indépendante par un radiologiste qui n'était pas au courant des détails cliniques.

RÉSULTATS : L'étude rétrospective a permis de repérer 41 patients ayant une bronchiectasie parmi 490 patients ayant une maladie pulmonaire. À deux occasions, la numération cellulaire totale de $60 \times 10^{6} / \mathrm{g}$ ou plus des expectorations sélectionnées et des neutrophiles prédominants avaient une sensibilité de $86,7 \%$, une spécificité de $87,5 \%$ et une valeur prédictive positive et négative de $93 \%$ et de $78 \%$, respectivement, pour dépister la bronchiectasie. Dans l'étude rétrospective, les chercheurs ont établi que dix des 14 (71\%) patients respectant ces critères avaient une bronchiectasie. La numération cellulaire totale et le pourcentage de neutrophiles étaient tous deux corrélés avec la gravité de la bronchiectasie à la radiographie.

CONCLUSIONS : Une intense cellularité des expectorations, persistante ou récurrente, accompagnée de neutrophiles, est évocatrice d'une bronchiectasie.

between January 2004 and January 2005 was used for the analysis. Sputum cell counts are generally requested by physicians to 'optimize current anti-inflammatory therapy' (50\%), 'assess bronchitis' (30\%) and for 'regular monitoring' (20\%). HRCT scans of thorax were available for $98(20 \%)$ of these patients. These scans were ordered by their physicians $(n=6)$ for various clinical suspicions and indications (evaluation of nodules [ $n=30]$, bronchiectasis [ $n=24]$, abnormal hila $[n=14]$, pleural disease $[n=12]$, chronic cough $[n=8]$, not specified $[n=10]$ ). The predictive value of sputum cell counts to identify bronchiectasis was evaluated in these 98 patients by creating $2 \times 2$ contigency tables using criteria of persistent neutrophilic bronchitis as described below. The cut-off values of sputum total cell count (TCC) and neutrophil percentage identified in the current retrospective survey were then validated prospectively in another 14 patients (February 2005 to April 2008) with recurrent intense sputum neutrophilia using thoracic HRCT scans. The scans were scored by a radiologist who was blinded to the clinical details and sputum cell counts. The study was approved by the Research Ethics Board of St Joseph's Healthcare and McMaster University (Hamilton, Ontario).

Sputum was induced by hypertonic saline, selected from the expectorate and processed according to the methods initially described by Pizzichini et al (6). The induction was performed by pulmonary function laboratory staff. The processing and examination of the sputum was performed in the hospital sputum laboratory by certified medical laboratory technologists trained in cell morphology

${ }^{1}$ Division of Respirology; ${ }^{2}$ Department of Diagnostic Imaging, St Joseph's Healthcare and McMaster University, Hamilton, Ontario

Correspondence: Dr Parameswaran Nair, Firestone Institute for Respiratory Health, St Joseph's Healthcare, 50 Charlton Avenue East, Hamilton,

Ontario L8N 4A6. Telephone 905-522-1155 ext 35044, fax 905-521-6183, e-mail parames@mcmaster.ca 
TABLE 1

Sputum cell counts, spirometry and clinical characteristics of patients with or without bronchiectasis

\begin{tabular}{|c|c|c|c|}
\hline & \multicolumn{2}{|c|}{ Bronchiectasis } & \multirow[b]{2}{*}{$\mathbf{P}$} \\
\hline & Yes $(n=41)$ & No $(n=57)$ & \\
\hline Sputum TCC, $10^{6} / \mathrm{g}$ & $48.2 \pm 22.4$ & $12.6 \pm 16.6$ & $<0.05$ \\
\hline Sputum n, \% & $78.2 \pm 24.4$ & $64.4 \pm 28.4$ & $<0.05$ \\
\hline Sputum Eo, \% & $5.6 \pm 2.3$ & $3.8 \pm 4.4$ & NS \\
\hline $\mathrm{FEV}_{1}, \mathrm{~L}$ & $2.1 \pm 1.6$ & $2.3 \pm 1.9$ & NS \\
\hline $\mathrm{FEV}_{1}, \%$ & $66.4 \pm 32.4$ & $68.5 \pm 35.5$ & NS \\
\hline $\mathrm{FEV}_{1} / \mathrm{VC}, \%$ & $68.4 \pm 33.4$ & $72.4 \pm 31.2$ & NS \\
\hline Male, $\mathrm{n}$ & 27 & 30 & NS \\
\hline Ever smoked, \% & 38 & 34 & NS \\
\hline Atopy, \% & 24 & 28 & NS \\
\hline ICS, $\%$ & 78 & 82 & NS \\
\hline
\end{tabular}

Data presented as mean $\pm S D$ unless otherwise indicated. Eo Eosinophils; FEV 1 Forced expiratory volume in $1 \mathrm{~s}$; ICS Inhaled corticosteroids; NS Not statistically significant; TCC Total cell count; VC Vital capacity

\section{TABLE 2}

\section{Association between bronchitis phenotype and} bronchiectasis

\begin{tabular}{lcc}
\hline & \multicolumn{2}{c}{ Bronchiectasis } \\
\cline { 2 - 3 } & Yes $(\mathbf{n = 4 1 )}$ & No $(\mathbf{n = 5 7})$ \\
\hline Neutrophilic bronchitis & 20 & 14 \\
Eosinophilic bronchitis & 16 & 15 \\
Normal cell count & 5 & 28 \\
\hline
\end{tabular}

Data presented as $n$

and in the examination of sputum. Processing involved selection of sputum from the expectorate using an inverted microscope, treatment with dithiothreitol to disperse mucus, filtration, measurement of TCC (expressed as million cells/g of selected sputum) and cell viability in a hemocytometer, and of differential count on Wright-stained cytospins. The quality control of the procedure and results were validated by the use of a standardized procedure and intra- and interlaboratory reliability of differential cell counts. Neutrophilic bronchitis was defined as a TCC of 15 million cells/g sputum or greater and a neutrophil count of $80 \%$ or greater. Eosinophilic bronchitis was defined as a proportion of eosinophils greater than $3 \%$. Persistent or recurrent neutrophilia or eosinophilia were defined as these criteria being met on two or more occasions. Repeat sputum cell counts (no more than 10 weeks apart) were available for 79 of the 98 patients included in the analysis.

High-resolution images were obtained in full inspiration using one of three HRCT scanners (GE Genesis HiSpeed RP, GE Lightspeed Pro16 or GE Lightspeed VCT, GE HealthCare, USA). Thin collimation images $(1.0 \mathrm{~mm}$ to $1.25 \mathrm{~mm})$ were acquired intermittently or helically through the thorax. The HRCT scans were blindly reviewed by a radiologist (RR) with seven years' experience in reading HRCT scans. Bronchiectasis was diagnosed when the airway was larger than the accompanying branch of the pulmonary artery. The severity of bronchiectasis was based on the following nine criteria for grading airway and parenchymal changes in cystic fibrosis patients: bronchiectasis; peribronchial thickening; mucus plugging; abscesses or bronchiectatic sacculations; bullae; emphysema; and collapse/consolidation. The HRCT score of each patient was calculated on the basis of the severity and/or extent of the nine morphological changes listed. The first seven findings were scored between 0 and 3 , while the latter two abnormalities were graded between 0 and 2 . The highest possible score was 25 . This scoring system has been used in previous studies with low interobserver variation $\left(K_{w} 0.87\right)(7,8)$.

\section{Analysis}

Between-group comparisons were made using the Mann-Whitney U test. The proportion of patients with neutrophilic and eosinophilic bronchitis with bronchiectasis was compared using the $\chi^{2}$ statistic.
TABLE 3

Association between phenotype of persistent bronchitis and bronchiectasis*

\begin{tabular}{lcc}
\hline & \multicolumn{2}{c}{ Bronchiectasis } \\
\cline { 2 - 3 } & Yes $(\mathbf{n = 4 1 )}$ & No $(\mathbf{n = 5 7 )}$ \\
\hline Persistent neutrophilic bronchitis & 12 & 10 \\
Persistent eosinophilic bronchitis & 5 & 14 \\
\hline
\end{tabular}

Data presented as $n$. *A greater proportion of patients with persistent neutrophilic bronchitis (12 of 22) has bronchiectasis compared with the proportion of patients with persistent eosinophilic bronchitis (five of 19)

The predictive value of cell counts for bronchiectasis was analyzed using logistic regression analysis (step-wise backward elimination method). The variables examined were the following: neutrophils (\%); TCC $\left(10^{6} / \mathrm{g}\right.$ of selected sputum); color of sputum (purulent, mucopurulent or mucoid); and persistence or recurrence of neutrophilia on more than one occasion. The analysis was controlled for smoking and current use of inhaled or ingested corticosteroids as covariates. The measurement properties of high TCC were examined by ROC curve analysis. Correlation between bronchiectasis score and sputum total and differential neutrophil counts were examined using Pearson's correlation. All analyses were performed using SPSS version 15.0 (SPSS, USA) for Windows (Microsoft Corporation, USA).

Retrospective study

\section{RESULTS}

Of the 98 patients who underwent HRCT scans, 41 (42\%) had bronchiectasis; of these, five also had asthma, 18 had emphysema, 14 had chronic bronchitis and four had nonasthmatic, nonsmoker chronic cough. Twenty of the 41 patients had neutrophilic bronchitis, 16 had eosinophilic bronchitis and five had normal sputum (Table 1). The proportion of patients with specific types of bronchitis and bronchiectasis was not significantly different compared with the proportion without bronchiectasis (Table 2). However, a significantly higher proportion of patients with persistent or recurrent neutrophilia (55\%) had bronchiectasis compared with patients exhibiting persistent or recurrent eosinophilia $(26 \%)(\mathrm{P}<0.05)$ (Table 3$)$.

In the logistic regression model, raised neutrophil count (OR 3.1 [95\% CI 1.1 to 7.2]) and persistent or recurrent raised TCC (OR 2.9 [95\% CI 1.4 to 4.8]) were predictors of bronchiectasis. Sputum colour or eosinophilia were not significant predictors of bronchiectasis. There were insufficient measures (and patients) to examine the effect of the extent and morphology of bronchiectasis on sputum cell counts.

ROC characteristics (Figure 1) showed that a TCC of 60 million cells/g or greater had a sensitivity of $86.7 \%$, a specificity of $87.5 \%$, a positive predictive value of $93 \%$ and a negative predictive value of $78 \%$ to identify bronchiectasis.

\section{Prospective study}

Ten of the 14 patients with prespecified sputum neutrophilia (TCC 60 million cells/g, neutrophils $80 \%$ or greater on two occasions) had evidence of bronchiectasis on HRCT. The mean $( \pm \mathrm{SD})$ bronchiectasis score was 5.8 \pm 5.2 ; the median score was 4.0 (minimum 0 , maximum 17). TCC and neutrophil percentage correlated significantly with the extent of bronchiectasis (TCC versus bronchiectasis score $\mathrm{R}=0.6(\mathrm{P}=0.037)$; neutrophils percentage versus bronchiectasis score $\mathrm{R}=0.6(\mathrm{P}=0.026)$.

\section{DISCUSSION}

We provide preliminary evidence that persistent or recurrent intense cellularity in selected sputum with predominant neutrophilia can reliably identify bronchiectasis. This observation adds to the clinical utility of using quantitative cell counts in sputum for the evaluation and management of patients with obstructive airway diseases (9) and, if validated in a large prospective study, may potentially decrease the need for HRCT scans to detect bronchiectasis, thus limiting radiation exposure and its consequences (10). 
Our observations are consistent with previous reports in the literature. Gaga et al (4) reported an overall increase in total leukocyte cell numbers $\left(\mathrm{CD}_{4} 5^{+}\right)$and $\mathrm{CD} 3^{+} \mathrm{T}$ lymphocytes, neutrophils and macrophages in the bronchial mucosa of patients with postinfective bronchiectasis compared with healthy controls. In children and in adults, Guran et al (11) and Loukides et al (12), respectively, observed increased neutrophil counts in the sputum of patients with noncystic fibrosis stable bronchiectasis compared with healthy controls; furthermore, the counts correlated with the severity of bronchiectasis radiology scores. However, the counts were much lower than in our current series and within what we would consider in the normal range. This may be due to the different methods used for sputum processing that may have resulted in a loss of cells during filtration of the cell suspension. In addition to cell counts, products of neutrophil activation and neutrophil chemoattractants have also been reported to be increased in sputum and in serum of bronchiectasis patients. Patel et al (13) and Watt et al (14) have demonstrated high levels of interleukin-8 and interleukin- 6 in the sputum of patients with bronchiectasis compared with control populations. Other mediators such as leukotriene $\mathrm{B}_{4}$ and C5a with chemotactic activity for neutrophils have been identified in the bronchoalveolar lavage fluid of patients with bronchiectasis. Consistent with previous observations in asthma patients, sputum colour was not predictive of bronchiectasis (15). Contrary to a previous report by Wark et al (16), we did not observe an association between eosinophilic bronchitis and bronchiectasis, presumably because we had only three patients with allergic bronchopulmonary aspergillosis in our cohort. Corticosteroid treatment of concomitant airway diseases may have also suppressed sputum eosinophilia (17).

The strengths of the present study include the use of a validated, reliable, repeatable quantitative method to assess cell counts in sputum selected from saliva, the use of certified trained sputum staff, quality control and the blinded assessment of cell counts and radiology scores. The current study is the first to report the measurement properties of cell counts in sputum, which demonstrated that persistent or recurrent intense cellular sputum (high TCC) with predominant neutrophilia can accurately identify patients with bronchiectasis. The weaknesses of the current study include the small sample size, the use of convenience sampling, its retrospective design and inherent biases. The small sample size did not allow us to examine the relationship between cell counts and bronchiectasis within diagnostic categories of asthma and emphysema. The cross-sectional nature of the present study did not allow us to examine whether higher neutrophil counts preceded the appearance of bronchiectasis and whether they are temporally related to the progression of bronchiectasis. We limited our analyses to patients who were deemed clinically stable by the physicians who requested the HRCT scans and sputum examination; therefore, we were unable to comment on the nature of exacerbations or the microbiology of sputum. Similarly, we cannot comment on

\section{REFERENCES}

1. Mikami M, Llewellyn-Jones CG, Bayley D, Hill SL, Stockley RA. The chemotactic activity of sputum from patients with bronchiectasis. Am J Respir Crit Care Med 1998;157:723-8.

2. Fuschillo S, De Felice A, Balzano G. Mucosal inflammation in idiopathic bronchiectasis: Cellular and molecular mechanisms. Eur Respir J 2008;31:396-406.

3. Zheng L, Shum I, Tipoe G, et al. Macrophages, neutrophils and tumour necrosis factor-alpha expression in bronchiectatic airways in vivo. Respir Med 2001;95:792-8.

4. Gaga M, Bentley AM, Humbert M, et al. Increases in CD4+ $\mathrm{T}$ lymphocytes, macrophages, neutrophils and interleukin 8 positive cells in the airways of patients with bronchiectasis. Thorax 1998;53:685-91.

5. Jayaram L, Labiris NR, Efthimiadis A, Valchos-Mayer H, Hargreave FE, Freitag AP. The efficiency of sputum cell counts in cystic fibrosis. Can Respir J 2007;14:99-103.

6. Pizzichini E, Pizzichini MM, Efthimiadis A, Hargreave FE, Dolovich J. Measurement of inflammatory indices in induced sputum: Effects of

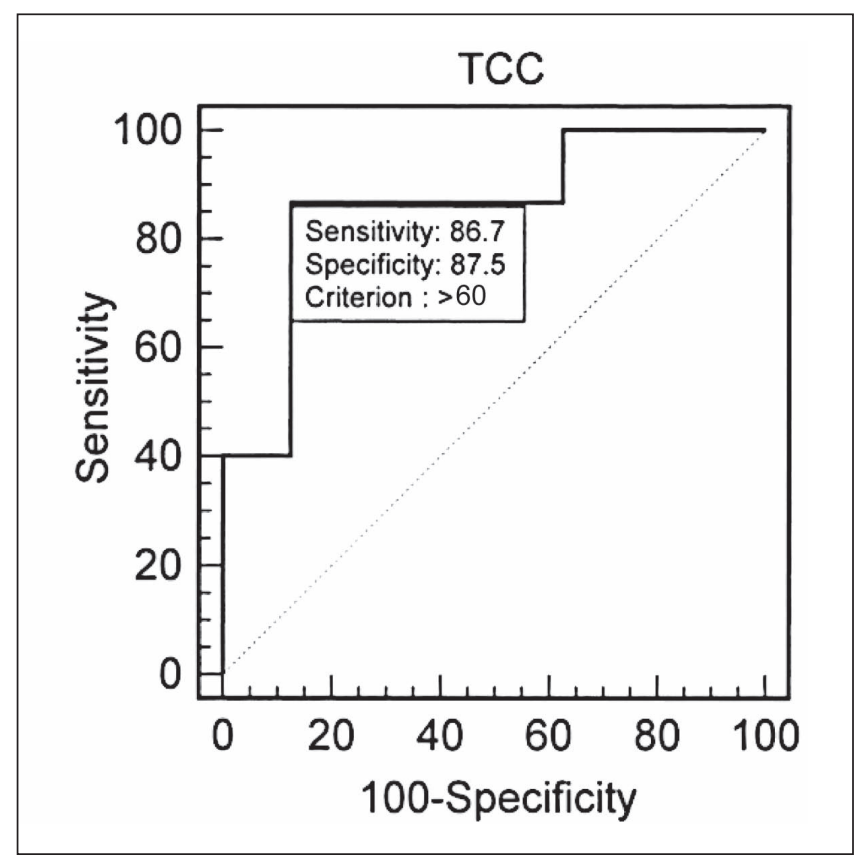

Figure 1) ROC curve identified a total cell count (TCC) of $60 \times 10^{6} / \mathrm{g}$ or greater of sputum with the highest sensitivity and specificity to detect bronchiectasis compared with the gold standard of high-resolution computed tomography ( $n=22$ patients with persistent neutrophilic bronchitis)

whether the intensity of bronchitis was related to bacterial colonization of the bronchiectactic airways or whether it was related to infection - these were not objectives of the present study. However, we realize that these are important future questions that need to be answered in future prospective studies.

\section{CONCLUSION}

We have demonstrated that persistent cellularity in sputum with predominant neutrophilia may reliably identify bronchiectasis and, therefore, be an alternative to thoracic HRCT scans. It remains to be answered whether this represents microbial colonization or persistent infection, and requires validation in a larger prospective study.

ACKNOWLEDGEMENTS: Dr Nair holds a Canada Research Chair in Airway Inflammometry. Dr D'silva was supported by an unrestricted educational grant from Merck Frosst Canada Inc. 
12. Loukides S, Bouros D, Papatheodorou G, et al. Exhaled $\mathrm{H}_{2} \mathrm{O}_{2}$ in steady-state bronchiectasis. Chest 2002;121:81-7.

13. Patel IS, Vlahos I, Wilkinson T, Lloyd-Owen S, Donaldson G, Wilks M. Bronchiectasis, exacerbation indices and inflammation in chronic obstructive pulmonary disease. Am J Respir Crit Care Med 2004;170:400-7.

14. Watt AP, Brown V, Courtney J, et al. Neutrophil apoptosis, proinflammatory mediators and cell counts in bronchiectasis. Thorax 2004;59:231-6.
15. Berlyne GS, Efthimiadis A, Hussack P, Groves D, Dolovich J, Hargreave FE. Sputum in asthma: Color versus cell counts. J Allergy Clin Immunol 2000;105:182-3.

16. Wark PAB, Saltos N, Simpson J, Slater S, Hensley MJ, Gibson PG. Induced sputum eosinophils and neutrophils and bronchiectasis severity in allergic bronchopulmonary aspergillosis. Eur Respir J 2000;16:1095-101.

17. Tsang KW, Ho P, Lam W, et al. Inhaled fluticasone reduces sputum inflammatory indices in severe bronchiectasis. Am J Respir Crit Care Med 1998;158:723-7. 


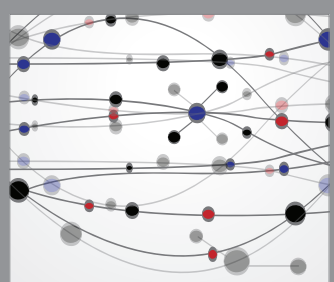

The Scientific World Journal
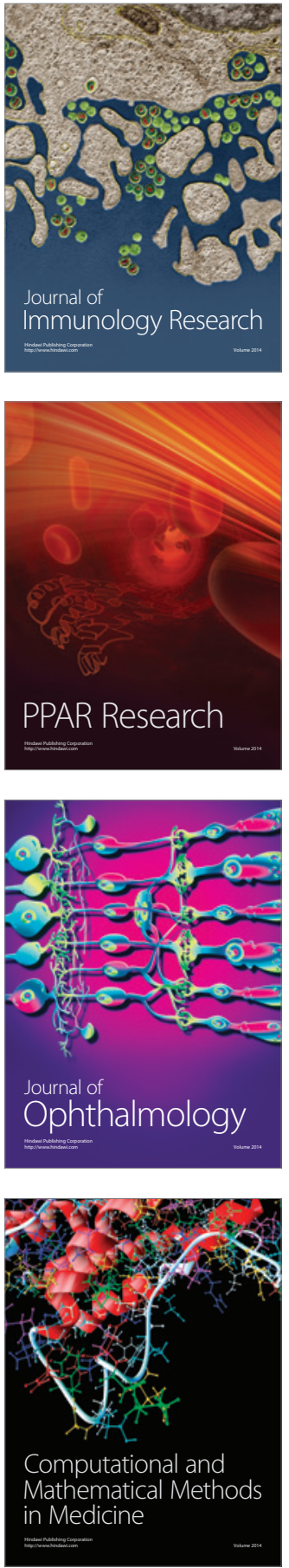

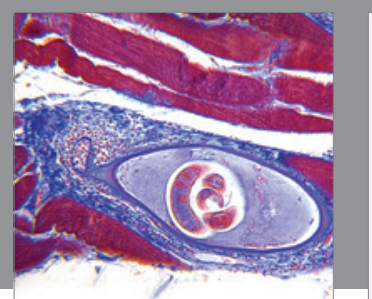

Gastroenterology Research and Practice

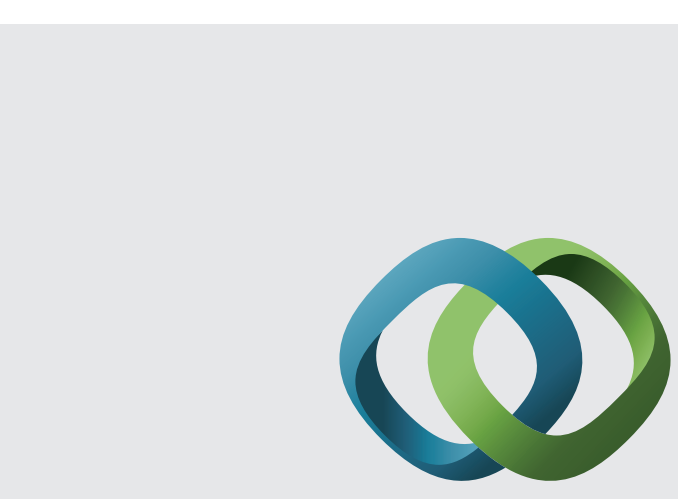

\section{Hindawi}

Submit your manuscripts at

http://www.hindawi.com
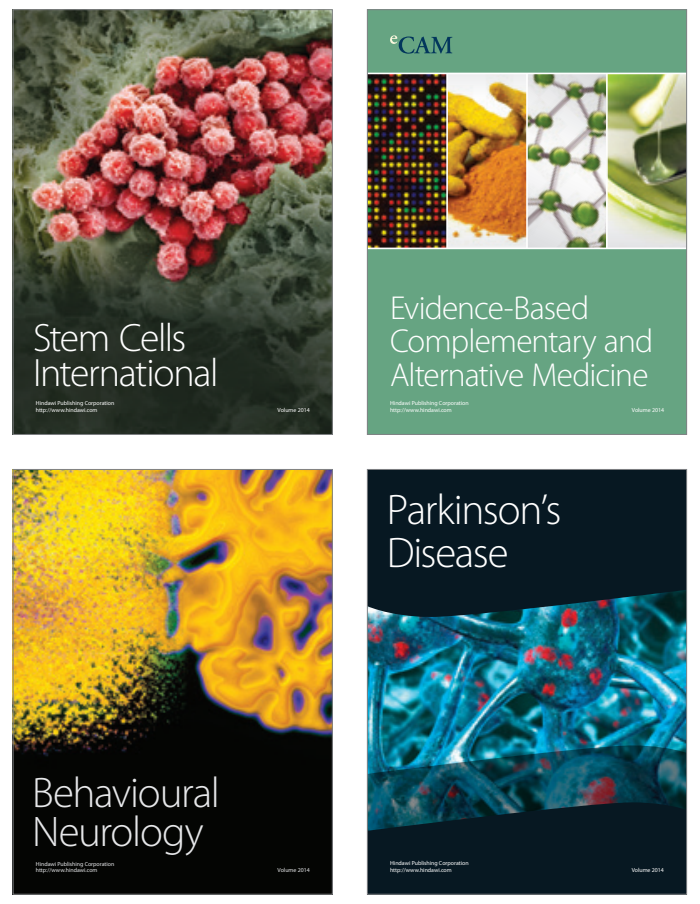
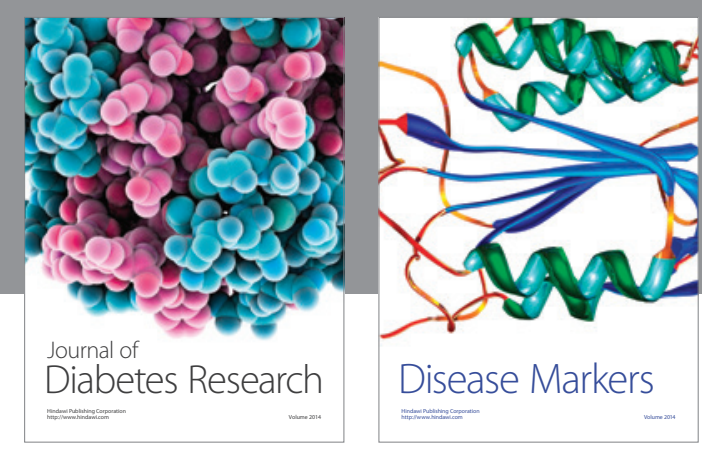

Disease Markers
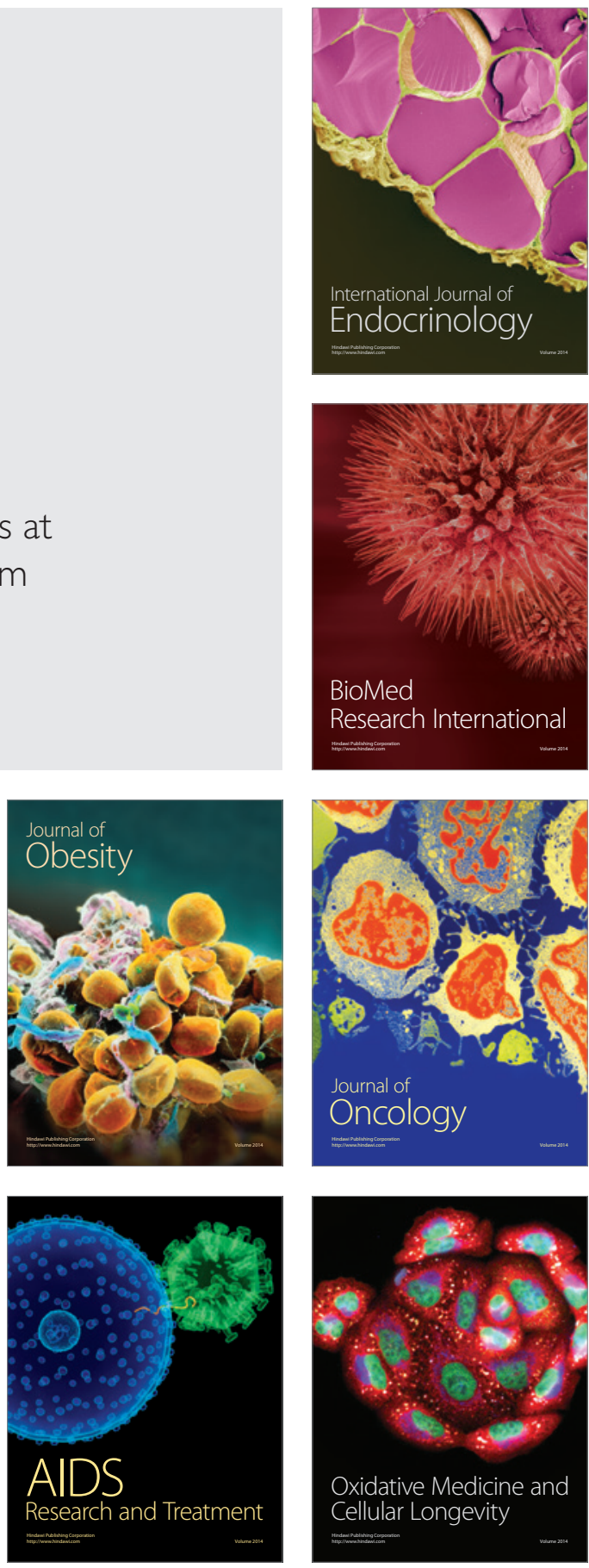